\title{
Common lower urinary tract fistulas: A review of clinical presentations, causes and radiographic imaging
}

\author{
Wanaporn Burivong, Vichit Leelasithorn, Vithya Varavithya
}

\begin{abstract}
Common lower urinary tract fistulas can present as uroenteric fistulas, urogenital fistulas and urocutaneous fistulas. They usually occur as sequel after pelvic surgery, obstetric complications following childbirth and gynecologic procedures. In patients with underlying neoplasm, fistulas may occur from primary or recurrent tumors and as a consequence of pelvic irradiation. Infectious process, trauma and congenital abnormalities can also cause lower urinary tract fistulas. Clinical presentation depends on the location and type of fistula. Radiographic imaging can give diagnosis and demonstrate associated complications of fistulas. Being familiar with clinical signs and symptoms as well as
\end{abstract}

choosing the appropriate imaging modality and technique are important. This article reviews common types of lower urinary tract fistulas correlated with their cause, clinical presentation and imaging modalities for diagnosis.

Keywords: Fistula, Lower urinary tract, Etiology, Clinical symptom, Radiographic imaging

$* * * * * * * * *$

Burivong W, Leelasithorn V, Varavithya V. Common lower urinary tract fistulas: A review of clinical presentations, causes and radiographic imaging. International Journal of Case Reports and Images 2011;2(1):1-7.

$* * * * * * * * *$.

doi:10.5348/ijcri-2011-01-13-RA-1

\section{INTRODUCTION}

Fistulas involving the lower urinary tract usually occur in patients with underlying pelvic diseases. They can communicate with the gastrointestinal tract, female reproductive tract or skin. Common causes of these fistulas are from post surgical and obstetric complications as well as post pelvic irradiation. Other etiologies are pelvic malignancy, infectious process, inflammatory disease, trauma and congenital conditions [1]. Lower urinary tract fistulas may be suggested by clinical manifestation and physical examination. Radiographic contrasted imaging can confirm the presence of fistula, give accurate diagnosis about the correct type and location of fistula, and demonstrate complications such as abscess formation [2]. The appropriate imaging study depends on the 
anatomic location and type of fistula. Lower ureteric fistulas can be demonstrated by excretory urography, retrograde urography and cross-sectional contrast imaging. Bladder fistulas are detected by cystography, voiding cystourethrography (VCUG) and computed tomography (CT scan). Retrograde urethrography and VCUG are useful methods for visualizing urethral fistulas. To demonstrate uroenteric fistulas, barium enema examination and oral contrast CT scan without intravenous enhancement can be used. Fistulography can confirm the present of urocutaneous fistulas [2-7].

Other genitourinary tract fistulas can occur in the upper urinary tract including renal fistulas and fistulas of the pelvocalyceal system. They may communicate with the bowel, skin, blood vessel and lymphatic system.

\section{LOWER URETERIC FISTULAS}

Classification based on site: Two common types of lower ureteric fistulas are ureterovaginal fistulas and ureteroenteric fistulas. Other uncommon types are ureterovascular and ureterocutaneous fistulas, which are not discussed in this article.

\section{Ureterovaginal Fistula}

\section{Definition}

Ureterovaginal fistula is a communication between the ureter and the vagina. The urine flows directly from the ureter into the vagina without passing into the bladder.

\section{Etiology}

Pelvic surgery and obstetric complications are common causes. Pelvic radiation therapy, infectious process and urinary calculi can also lead to this type of fistula.

\section{Clinical presentation}

Most of the patients present with urine leakage from vagina. Abdominal pain, flank pain, fever and paralytic ileus may also develop.

\section{Radiographic diagnosis}

Preliminary test: Excretory urography is one of the common radiographic contrast study used as an initial test to diagnosis this fistula group. Extravasation outside the ureter, drainage of contrast media into vagina or evidence of hydronephrosis and hydroureter without vaginal drainage may be the presenting complaints. Demonstrable fistulous tract from ureter to vagina can be seen in some cases $[1,3-5]$. The sensitivity of excretory urography in detecting ureterovaginal fistula is about $33 \%$ [1]. Even though the sensitivity of this test is quite low, it's still widely used because of its non-invasive technique.

Confirmatory test: If the fistulous site is difficult to locate, retrograde pyelography should be the definite test [8].

Other tests used: Delayed contrast-enhanced CT scan and vaginography are alternative choices for investigation $[3,8]$.

\section{Ureteroenteric fistula}

\section{Definition}

Ureteroenteric fistula connects the ureter to the alimentary tract.

\section{Etiology}

Ureterocolic fistula is the most common type of ureteroenteric fistula. Etiologies include colorectal malignancy, post pelvic surgery, radiation therapy and spontaneous fistulas. Spontaneous ureteroenteric fistulas are mostly caused by ureteric calculi or infectious process such as diverticulitis of the colon and tuberculosis. Ureteroileal fistulas are less common. It may occur from inflammatory bowel disease especially Crohn's disease, accidental trauma and iatrogenic causes [3,9].

\section{Clinical presentation}

Patients can present with abdominal or flank pain, hematuria, recurrent urinary tract infection, pneumaturia, fecaluria and diarrhea.

Radiographic diagnosis

Preliminary test: Barium enema is the most helpful diagnostic test in this type of fistula. Because the mean pressure in alimentary tract is usually higher than the urinary tract, therefore, contrast media from the alimentary tract usually flows into the urinary system [5]. However, fistulous tract is difficult to detect. Mucosal abnormality of the bowel such as bowel wall irregularity is the clue for diagnosis [3].

Confirmatory test: CT scan is good for demonstrating associated intra-abdominal lesions such as collection, abscess formation or recurrent tumor [2].

Other tests used: Other diagnostic methods are excretory urography and retrograde urethrography which are usable in conditions when contrast media in the urinary system flows into the alimentary tract (Figure 1).

\section{BLADDER FISTULAS}

Classification bases on site

Common types of bladder fistulas are enterovesical fistulas, vesicovaginal fistulas and vesicocutaneous fistulas. Vesicouteric fistula occur but are not common.

\section{Enterovesical fistula}

Definition

Enterovesical fistula connects the bladder to the small bowel or large bowel. 

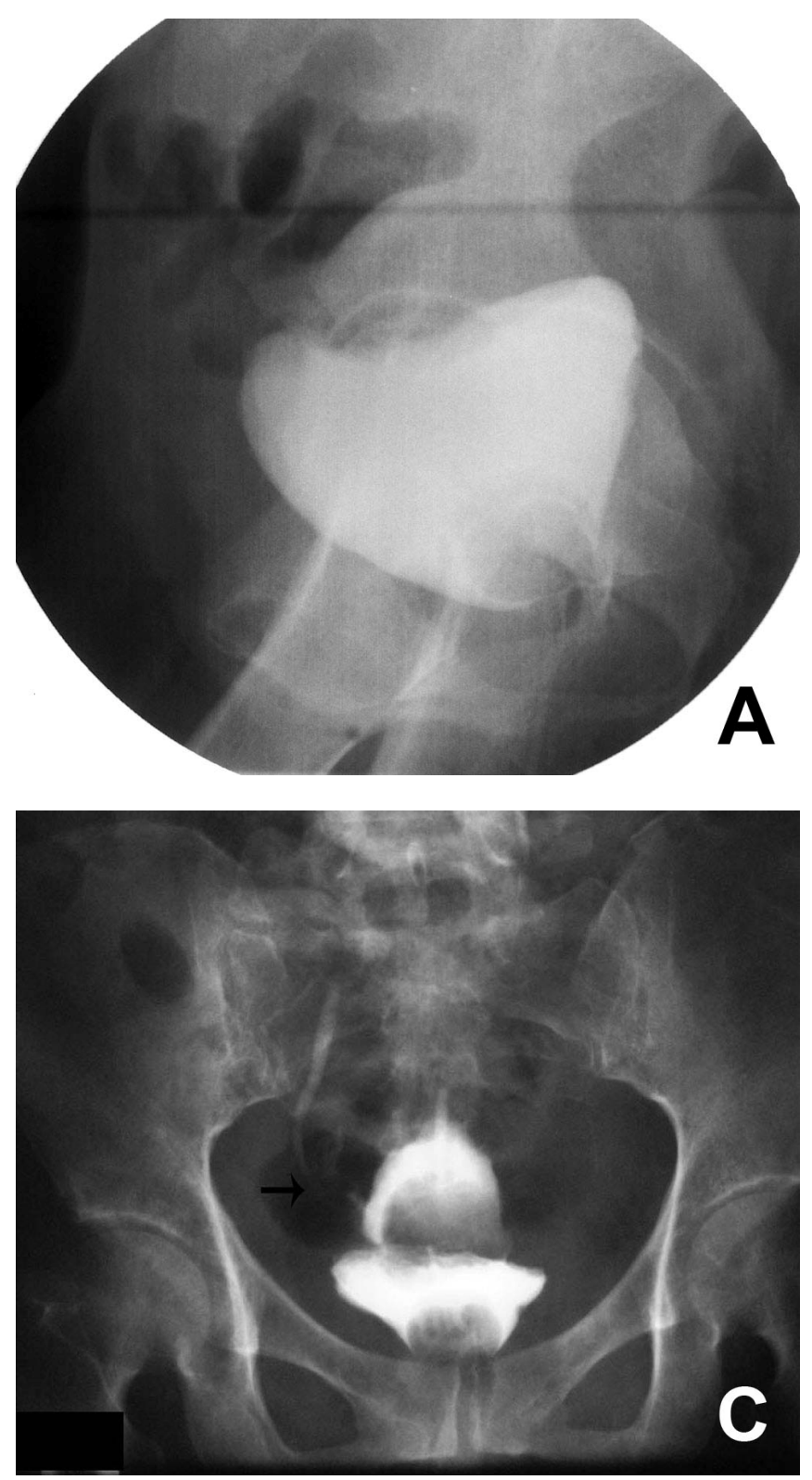

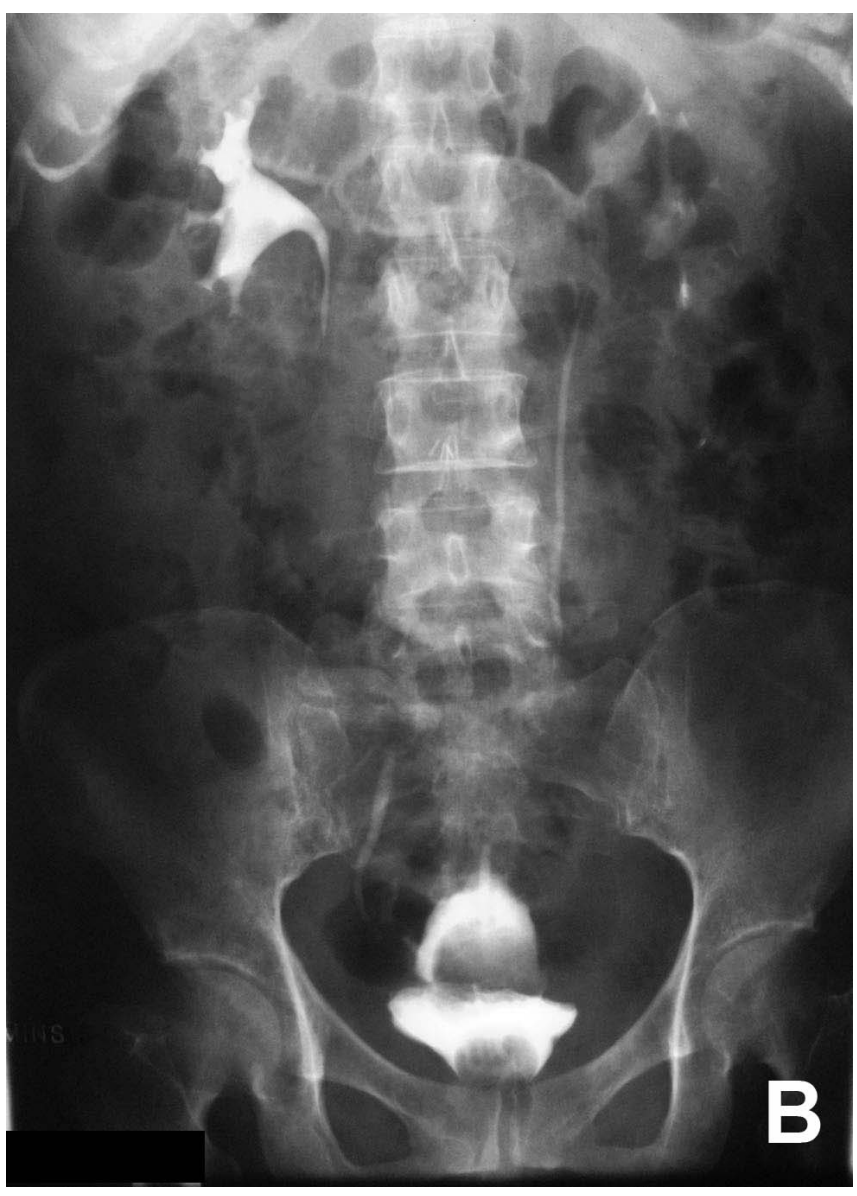

Figure 1: Ureterorectal fistula in a patient with fecaluria after abdominoperineal resection with end colostomy due to rectosigmoid carcinoma. A) - Cystography shows normal appearance by which vesicorectal fistula could be excluded. B) - Excretory urography reveals right hydronephrosis and presence of contrast media in the rectum. C) - Spot image at bladder demonstrates contrast material from right distal ureter draining into rectum (arrow).

\section{Etiology}

Trauma and neoplasm of the gastrointestinal or genitourinary tract often connects the bladder to the rectum and create rectovesical fistulas. Colonic adenocarcinoma and diverticulitis are common causes of colovesical fistulas. Crohn's disease usually causes ileovesical fistulas. Pelvic surgery, radiation therapy, foreign body and infection such as tuberculosis and syphilis can also lead to enterovesical fistulas.

\section{Clinical presentation}

Patients may present with recurrent cystitis, pneumaturia, fecaluria, fever and abdominal pain.

\section{Radiographic diagnosis}

Preliminary test: Even though CT scan with oral contrast is the primary imaging modality, only $20-42 \%$ of fistulous tracts are visualized. Secondary signs are found more commonly. The suggestive signs of enterovesical fistulas are intravesicular air, presence of oral or rectal contrast in the urinary bladder, focal bladder wall thickening, thickening of adjacent bowel wall, and presence of extraluminal mass which contains air. (Figure 2)

Other tests used: Cystography is another reliable diagnostic method but less sensitive than CT. Its sensitivity is about $35-44 \%$. Barium enema can also be used for diagnosis. The sensitivity is equal to cystography but less accurate [3,10,11] (Figure 3).

\section{Vesicovaginal fistula}

\section{Definition}

Vesicovaginal fistula communicates the bladder to the vagina. 

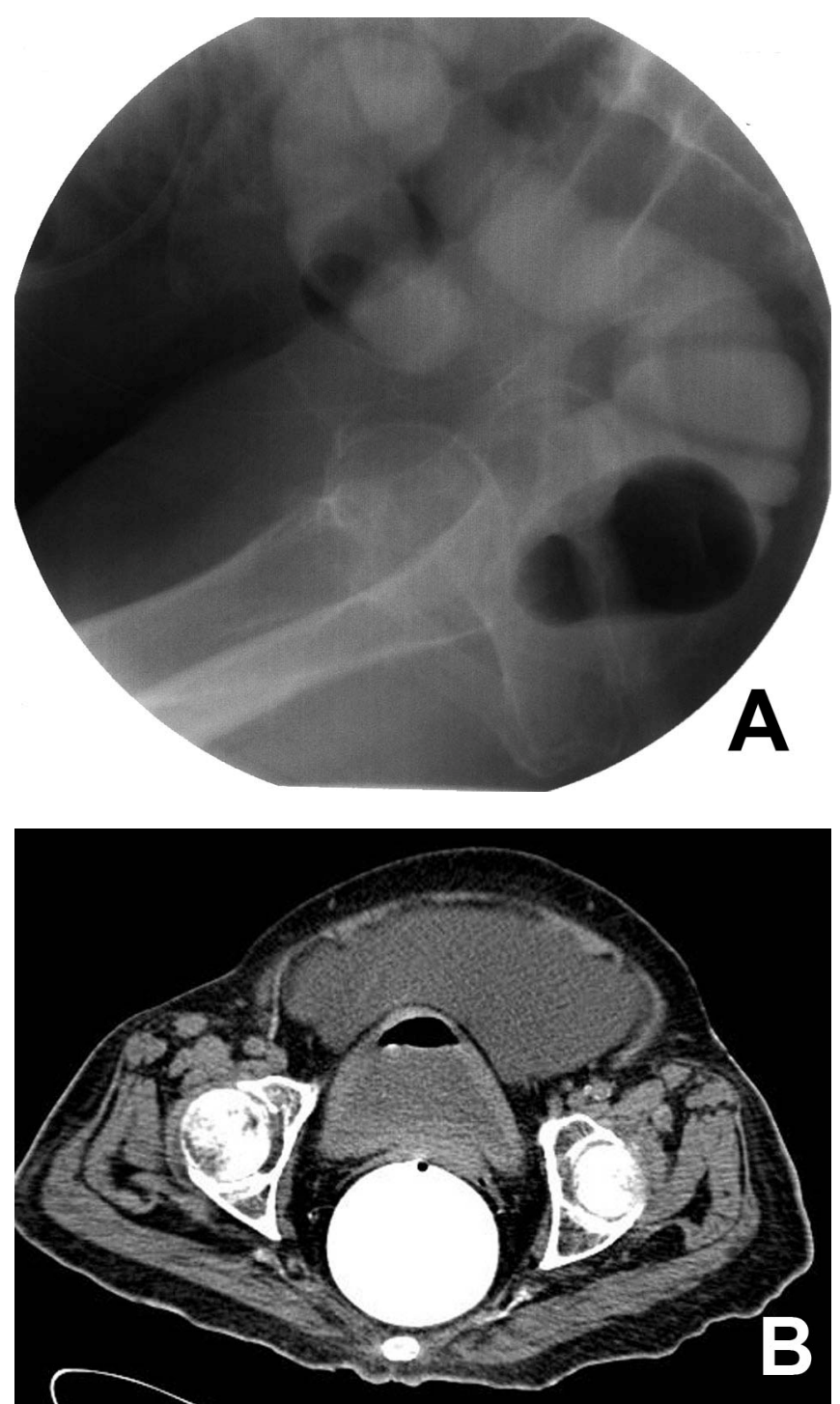

Figure 2: Enterovesical fistula in a patient with fecaluria. A) - Single contrast enema cannot detect any fistuous tract or contrast leakage. B) - CT section of the pelvis obtained after contrast enema shows air collection in the bladder which is a suggestive sign of enterovesical fistula.

\section{Etiology}

Vesicovaginal fistulas may be caused by surgical and obstetric complications, foreign bodies, catheters or infection such as tuberculosis or schistosomiasis. In patients with underlying malignancy, fistulas may occur from primary pelvic malignancies, recurrent neoplasm of the cervix, vagina and rectum or following radiation treatment. The most common cause of vesicovaginal fistulas in developing countries are from obstetric complication after childbirth, where as in developed countries, surgical procedures within the pelvis and complications after gynecologic procedures are more common.

\section{Clinical presentation}

Symptoms are watery leakage from vagina, menouria and perineal dermatitis.

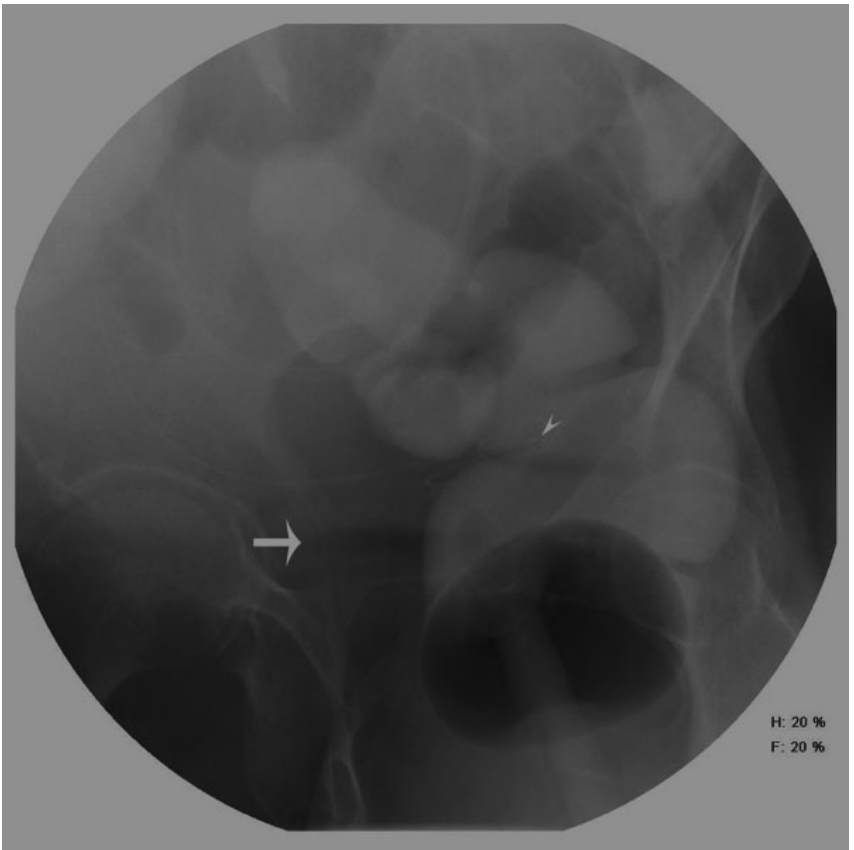

Figure 3: Enterovesical fistula in a female patient with endstage renal disease who is maintained on peritoneal dialysis. She presented with fecaluria. Double contrast barium enema shows intravesicular air (arrow) indicating enterovesical fistula. Peritoneal dialysis catheter is noted (arrowhead).

Radiographic diagnosis

Preliminary test: Cystography or VCUG in lateral view may demonstrate the fistulous tract. If the fistulous tract is small, voiding images are helpful.

Confirmatory test: Unenhanced CT scan followed by intravenous-contrast enhanced CT in excretory phase can detect fistulous connection between the bladder and vagina.

Other test used: Excretory urography can be used for excluding concomitant ureterovaginal fistula, but is not sensitive $[2,3,5,8,12]$. (Figure 4 )

\section{Vesicouterine fistula}

\section{Definition}

Vesicouterine fistula connects the bladder to the uterus.

\section{Etiology}

Vesicouterine fistula is less common. Obstetric complications following cesarean section, forceps extraction and curettage for removal of placenta are common causes. Complications following surgical procedures, perforation of intrauterine device and trauma may also lead to vesicouterine fistulas.

\section{Clinical presentation}

The suggestive symptom is intermittent urine leakage or urinary incontinence. Other symptoms 

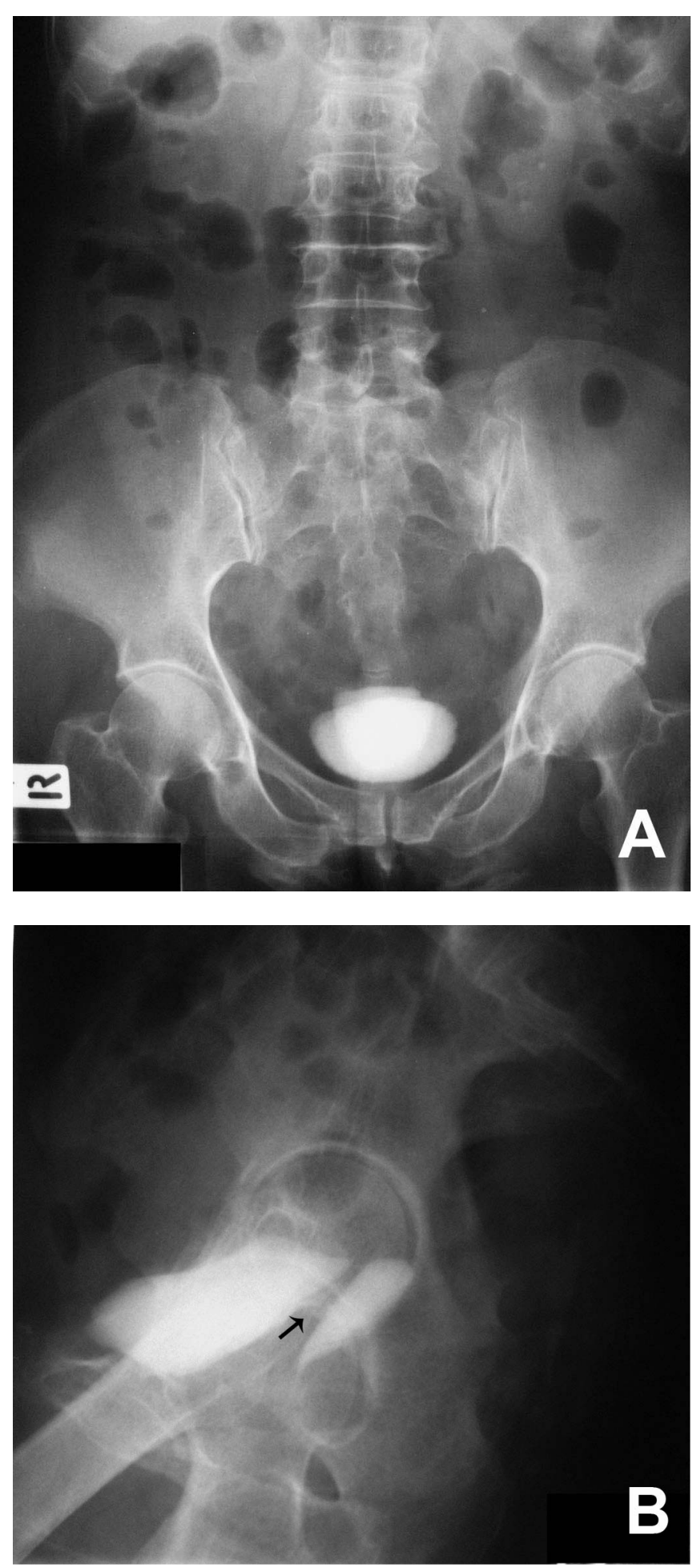

Figure 4: Vesicovaginal fistula in a patient with watery vaginal discharge after hysterectomy. A) - Excretory urography demonstrates contrast leakage from urinary bladder into the vagina. B) - Lateral view of excretory urogram shows a faint fistulous tract (arrow) between the bladder and vagina.

include cyclic hematuria, amenorrhea and urinary tract infection.
Radiographic diagnosis

Tests used: Conventional diagnostic methods are cystography, hysterography and excretory urography. Using excretory urography it is difficult to distinguish vesicovaginal fistula from vesicouterine fistula, because presence of contrast media in vagina is the only finding. Hysterography may show leakage of contrast media into the bladder. CT scan with intravenous contrast media or CT with sagittal reformation after hysterography is also diagnostic. However, results from these examinations are still inconclusive $[3,5,8]$.

\section{Vesicocutaneous fistula}

\section{Etiology}

Vesicocutaneous fistula occurs from surgical procedures, post radiation treatment, trauma and iatrogenic causes. It can also occur after removal of suprapubic cystostomy. Spontaneous vesicocutaneous fistula is rare.

\section{Radiographic diagnosis}

Tests used: Fistulography and cystography are used for diagnosis. CT scan is recommended if the fistulous tract is complex or to evaluate associated malignant neoplasm $[3,13,14]$.

\section{URETHRAL FISTULAS}

Classification based on site

Urethral fistulas may occur from congenital or acquired conditions. Types of urethral fistulas are urethrorectal fistulas, urethrocutaneous fistulas and urethrogenital fistulas.

\section{Urethrorectal fistula}

\section{Definition}

Urethrorectal fistula is not common. It connects the urethra and the rectum.

\section{Etiology}

In children, congenital anorectal anomaly is the cause. In adults, urethrorectal fistulas usually occur after prostate surgery, urethral instrumentation or due to fracture of the pelvis. Tubercular infection, genitourinary tumors and post radiation therapy can also develop this type of fistula.

\section{Clinical presentation}

Children usually present with meconium stained urine. Symptoms in adult are recurrent urinary tract infection, urine per rectum, fecaluria, hematuria and infection of the seminal vesicles.

\section{Radiographic diagnosis:}

Confirmatory test: VCUG and retrograde urethrography are used for diagnosis. In anteroposterior view, the fistulous tract may be 


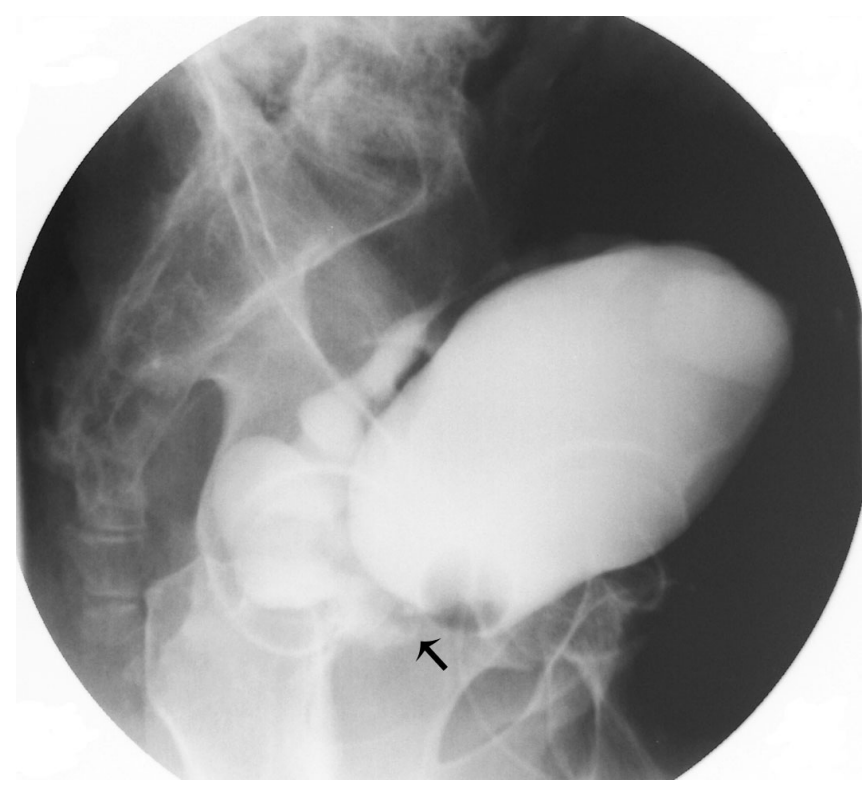

Figure 5: Urethrorectal fistula in a patient presenting with fecaluria from radical prostatectomy due to prostate cancer. Cystography shows leakage of contrast material from the vesicourethral anastomosis into the rectum. The presence of a fistulous tract between the bladder neck and rectum is observed (arrow).

obscured by overlying contrast medium in the rectum or urethra. Therefore, lateral view should be performed to demonstrate thin line of fistulous tract $[3,5,15,16]$. Urethrorectal fistulas occurring after radical prostatectomy are usually seen at the vesicourethral anastomosis. (Figure 5)

\section{Urethrocutaneous fistula}

\section{Definition}

Urethrocutaneous fistula connects the urethra with the skin. The most common type of urethrocutaneous fistula is the connection between the urethra and the perineum.

\section{Etiology}

Urethroperineal fistulas develop after infection such as chronic untreated periurethral abscess or parasitic infections. Trauma and complications after urethral or prostate gland surgery are also causes in adults. Congenital urethrocutaneous fistula is an uncommon developmental anomaly.

\section{Clinical presentation}

Patients usually present with perineal infection or dribbling of urine.

\section{Radiographic diagnosis}

Tests used: Conventional radiographic studies like VCUG, retrograde urethrography and fistulography can demonstrate the communication site. Associated complications such as abscess formation can be detected by CT scan $[3,5,17]$.

\section{Urethrogenital fistula}

\section{Definition}

Urethrogenital fistula is a communication between the urethra and the male or female reproductive tract.

\section{Etiology}

Urethrovaginal fistula is the common urethrogenital fistula in female. It results from post surgical procedure, obstetric complication, pelvic trauma, neoplasm and pelvic irradiation. Urethrovaginal fistulas may also develop after prolonged transurethral catheter with pressure necrosis. Urethrogenital fistula in male patient is rare. This condition can result from iatrogenic causes, blunt penile trauma or straddle injury. In children, congenital anomaly may also be the cause.

\section{Clinical presentation}

Patients with this type of fistula present with sustained watery leakage per vagina.

\section{Radiographic diagnosis}

Tests used: Although urethrovaginal fistulas can be identified by vaginal speculum examination and cystourethroscopy, radiographic diagnosis can be made by VCUG, sonography or delayed intravenous contrast-enhanced CT. Fistulous tracts in male patient can present with urethrography $[3,5,12,18]$.

\section{CONCLUSION}

Lower urinary tract fistulas usually occur in patients with underlying pelvic diseases. Its etiology includes congenital conditions in children, infectious processes, malignant tumors, trauma and pelvic irradiation as well as complications following obstetrics and surgical procedures. Clinical presentation depends on the type of fistula. Diagnosis usually requires radiographic imaging. Common conventional radiography used in the diagnosis of lower urinary tract fistulas are excretory urography, cystography, voiding cystourethrography, urethrography and barium enema. Cross-sectional imaging by CT scan, is considered as an imaging modality of choice in some type of cases. Otherwise, it is used in fistulas that are difficult to demonstrate by conventional method or to detect intraabdominal complications. The appropriate imaging modality and technique will lead to accurate diagnosis.

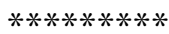

\section{Author Contributions}

Wanaporn Burivong - Conception and design, 
Acquisition of data, Analysis and interpretation of data, Drafting the article, Critical revision of the article, Final approval of the version to be published Vichit Leelasithorn - Analysis and interpretation of data, Critical revision of the article, Final approval of the version to be published

Vithya Varavithya - Analysis and interpretation of data, Critical revision of the article, Final approval of the version to be published

\section{Guarantor}

The corresponding author is the guarantor of submission.

\section{Conflict of Interest}

Authors declare no conflict of interest.

\section{Copyright}

(C) Wanaporn Burivong et. al. 2011; This article is distributed under the terms of Creative Commons attribution 3.0 License which permits unrestricted use, distribution and reproduction in any means provided the original authors and original publisher are properly credited. (Please see www.ijcasereportsandimages.com /copyright-policy.php for more information.)

\section{REFERENCES}

1. Avritscher R, Madoff DC, Ramirez PT, Wallace MF, Ahrar K, Morello FA et al. Fistulas of the lower urinary tract: percutaneous approaches for the management of a difficult clinical entity. Radiographics 2004;24:S217-S236.

2. Narayanan P, Nobbenhuis M, Reynolds KM, Sahdev A, Reznek RH, Rockall AG. Fistulas in malignant gynecologic disease: etiology, imaging, and management. Radiographics 2009;29:1073-1083.

3. Yu NC, Raman SS, Patel M, Barbaric Z. Fistulas of the genitourinary tract: a radiologic review. Radiographics 2004;24:1331-1352.

4. Randawa AJ, Khalid L, Abbas A. Diagnosis and management of ureterovaginal fistula in a resource constrained setting: experience at a district hospital in northern Nigeria. Lybyan Journal of Medicine 2009;4:41-43.

5. Moon SG, Kim SH, Lee HJ, Moon MH, Myung JS. Pelvic fistulas complicating pelvic surgery or diseases: spectrum of imaging findings. Korean $\mathrm{J}$ Radiol 2001;2:97-104.

6. Goldman SM, Fishman EK, Jones B, Siegelman SS. CT in the diagnosis of enterovesical fisulae. AJR Am J Roentgenol 1985;144:1229-1233.

7. Mamere AE, Coelho RD, Cecin AO, Feltrin LT, Lucchesi FB, Pinheiro MA. Evaluation of urogenital fistulas by magnetic resonance urography. Radiologia Brasileira [serial online]. 2008;vol41,no.1. Available at: www.scielo.br/scielo.php?pid=s010039842008000100007\&script=sci_arttext\&tlng=en. Accessed August 28, 2010.

8. http://emedicine.medscape.com/article/452934diagnosis

9. Albert AS, Chacko SA, Saju PR, Mathew G. Uretero- sigmoid fistula: a rare complication of vaginal hysterectomy. Indian J Urol 2002;18:159-160.

10. Outwater E, Schiebler ML. Pelvic fistulas: findings on MR images. AJR Am J Roentgenol 1993;160:327330.

11. http://urologysurgery.wordpress.com/2009/01/11/v esicoenteric-fistula/

12. Roth MG. Vesicovaginal and urethrovaginal fistulas. The global library of women's medicine [serial online]. Available at: www.glowm.com/index.html? $\mathrm{p}=$ glowm.cml/section_view\&articleid=64\&recordset $=$ Search results\&value $=$. Accessed August 29, 2010

13. Kishore TA, Bhat S, John PR. Vesicocutaneous fistula arising from a bladder diverticulum. Indian Journal of Medical Sciences 2005;59:265-267.

14. Lau KO, Cheng C. A case report: delayed vesicocutaneous fistula after radiation therapy for advanced vulvar cancer. Ann Acad Med Singapore 1998;27:705-706.

15. Kawashima A, Sandler CM, Wasserman NF, LeRoy AF, King BF, Goldman SM. Imaging of urethral disease: a pictorial review. Radiographics 2004;24:S195-S216.

16. Hanus T. Rectourethral fistulas. Int Braz J Urol 2002;28:338-345.

17. Gupta V, Sharma SB. Use of facia lata graft blanket wrap to prevent fistulas in hypospadias repair. J Indian Assoc Pediatr Surg 2006;11:89-91.

18. Pushkar DY, Dyakov VV, Kosko JW, Kasyan GR. Management of urethrovaginal fistulas. Eur Urol 2006;50:1000-1005. 